\title{
Entrepreneurial orientation on business performance for small, micro and medium enterprises in the telecommunications industry: A management perspective
}

\begin{tabular}{|c|c|}
\hline \multicolumn{2}{|c|}{$\begin{array}{l}\text { Author: } \\
\text { Medicine Magocha }{ }^{1}\end{array}$} \\
\hline \multicolumn{2}{|c|}{$\begin{array}{l}\text { Affiliation: } \\
{ }^{1} \text { Department of Economic } \\
\text { and Business Sciences, } \\
\text { Faculty of Commerce and } \\
\text { Administration, Walter } \\
\text { Sisulu University, } \\
\text { Mthatha, South Africa }\end{array}$} \\
\hline \multicolumn{2}{|c|}{$\begin{array}{l}\text { Corresponding author: } \\
\text { Medicine Magocha, } \\
\text { workhorsejn@gmail.com }\end{array}$} \\
\hline \multicolumn{2}{|c|}{$\begin{array}{l}\text { Dates: } \\
\text { Received: } 25 \text { Mar. } 2021 \\
\text { Accepted: } 12 \text { Sept. } 2021 \\
\text { Published: } 02 \text { Feb. } 2022\end{array}$} \\
\hline \multicolumn{2}{|c|}{$\begin{array}{l}\text { How to cite this article: } \\
\text { Magocha M. Entrepreneurial } \\
\text { orientation on business } \\
\text { performance for small, micro } \\
\text { and medium enterprises in } \\
\text { the telecommunications } \\
\text { industry: A management } \\
\text { perspective. J transdiscipl res } \\
\text { S Afr. } 2022 ; 18(1), \text { a } 1053 \text {. } \\
\text { https://doi.org/10.4102/td. } \\
\text { v18i1.1053 }\end{array}$} \\
\hline \multicolumn{2}{|c|}{$\begin{array}{l}\text { Copyright: } \\
\text { (c) 2022. The Author. } \\
\text { Licensee: AOSIS. This } \\
\text { is licensed under the } \\
\text { Creative Commons } \\
\text { Attribution License. }\end{array}$} \\
\hline \multicolumn{2}{|l|}{ Read online: } \\
\hline 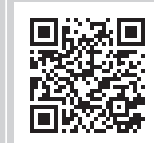 & $\begin{array}{l}\text { Scan this QR } \\
\text { code with your } \\
\text { smart phone or } \\
\text { mobile device } \\
\text { to read online. }\end{array}$ \\
\hline
\end{tabular}

Entrepreneurship is playing a mediating role in ensuring that the impact of climate and technological changes are regulated and made adaptable and adoptable for humanity through entrepreneurial innovations. In this article, a critical discourse analysis is conducted to establish the facts regarding the influential relationships affecting entrepreneurial orientation (EO) and business productivity for small, micro and medium enterprises (SMMEs) in the information and communications industry in Zimbabwe. An exploratory quantitative methodology using a positivist approach was applied to reinforce the independence of the researcher and to eliminate bias in the exploration of the orientations. Data were collected from 308 entrepreneurial entities located in different parts of the Harare urban zones, which were randomly sampled. One of the major findings of this research points conspicuously to the inevitability of EOs. Accordingly, it is recommended that enterprise regulators, legislators and the state should emphasise the inclusion of EO in the existing body of knowledge, and support telecommunications business practitioners to make significant decisions on strategic risk management when conducting strategic formulation and implementation.

Keywords: entrepreneurial orientation; business performance; enterprising; information and communications; technology.

\section{Background}

Entrepreneurship, like any other discipline and philosophy, is progressing tremendously in tandem with demographic parabolic shifts. The Green Revolution of the 1950s and 1960s, the Industrial Revolution, spanning from the first to the current Fourth Industrial Revolution (4IR) of 1760 to sometime between 1820 and $1840,{ }^{1}$ and resurfacing as the 4 IR of the 21st century, have triggered climate change, economic growth, and technological advancement. ${ }^{2}$ The small, micro and medium enterprises (SMME) sector and in particular the telecommunications sector is under public scrutiny in Zimbabwe. There has been public interest in the issues that are leading to the varied fortunes in the sector. This research seeks to annex knowledge on entrepreneurial orientation (EO) and support information pertaining to communications business entrepreneurs to make considerations with regard to strategic risk when conducting strategic formulation and implementation. ${ }^{3}$ This article will assist information and communications business owners in incorporating EO in the strategy development for their businesses. It will assist the stakeholders involved in the telecommunications sector in Zimbabwe to consider the aspects related to EO with due diligence in their information and communications supplier recruitment processes. The article proposes the shaping of policy underpinning sustained competitive advantage for firms in the telecommunications sector. It seeks to close the gap in research as no studies have to date been carried out in Zimbabwe on EO for SMMEs in the telecommunications industry that can help shape policy formulation for business entrepreneurs to enable them to grow and sustain their businesses in the long term.

The historical background of the EO concept has been discussed in several studies including Anderson, Kreiser, and Kuratko, ${ }^{4}$ Basso and Fayolle, ${ }^{5}$ Covin and Wales, ${ }^{6}$ Edmond and Wiklund, ${ }^{7}$ and Miller. ${ }^{8}$ Covin and Lumpkin ${ }^{9}$ noted that hypothetical approval of the EO concept entrepreneurship is simply adjudged as a singular act or activity, such as the launching of an invention, whereas it is in fact an overall strategic outlook. The EO has been designated in diversified manner in the past research. Anderson and Shemilt ${ }^{10}$ proposed a brief, yet all-inclusive 
definition of EO as being a firm's managerial philosophies, decision-making practices and strategic behaviours that are inherently entrepreneurial. The EO has been traditionally identified as a firm-level overarching strategic outlook involving risk-taking, proactiveness and innovativeness. These dimensions are gleaned from Danny Miller's early work on firms' strategy-making. ${ }^{7,8}$

\section{Introduction}

The world over, shifts in population demographics, technological developments, economies, corporate social responsibility (CSR) and sustainability considerations are transforming societies in magnitudes never previously experienced, exposing humanity to new challenges and opportunities. Chief among these shifting forces is an accentuation on entrepreneurship by governments, businesses, and the public. ${ }^{11}$ The SMMEs world over have become integral participants in mainstream economic activities in many countries. Lukes and Laguna ${ }^{12}$ postulated that SMMEs are creating critically needed employment, and therefore are considered a paramount influence in a free-market economy. The growth of SMMEs is a fundamental constituent of competitive and sustainable development in smaller economies such as Zimbabwe. Entrepreneurial orientation has become an established construct in entrepreneurship and the wider management research, and several recent reviews of the EO literature have been conducted. ${ }^{13} \mathrm{~A}$ number of relationships that are widely accepted in entrepreneurship include an important one between EO and organisational accomplishment. Research on EO is accelerating and broadening, gaining consequential traction in scholarly outlets beyond solely the entrepreneurship domain-specific journals. ${ }^{14}$

\section{Small micro and medium enterprises in Zimbabwe since 2008}

Growth in SMMEs is a crucial constituent in developing economies. However, the growth and evolution of SMMEs in Zimbabwe is undermined by a myriad of issues that result in higher rates of failure for such organisations. ${ }^{15} \mathrm{~A}$ World Bank ${ }^{16}$ report in 2016 indicated that about $60 \%$ of the SMMEs in Zimbabwe collapse in the first year of starting operations, while $25 \%$ fall short of their third anniversary, and only the remaining $15 \%$ survive. This research established that about $85 \%$ of SMMEs in Zimbabwe do ultimately collapse. Yet, in 2019 this study indicated that SMEs in Telecommunications industry in Zimbabwe contribute about $70 \%$ of the gross domestic product (GDP) annually, at the same time employing $90 \%$ of the total workforce. Moreover, this study shows that the number of the SMMEs in the telecommunications industry is growing at an average of $20 \%$ per annum.

Accordingly, in this current study $75 \%$ of the SMMEs in the telecommunications industry in Zimbabwe pursue different approaches to growth, and $45 \%$ of the stipulated $75 \%$ have stagnated and suffered from the growth crisis syndrome. It is this backdrop that aroused the interest of the researcher in the current study. There are many theories that deal with the significance, contribution and function of SMMEs regarding the growth of the national economy. The role of entrepreneurs in SMMEs in the telecommunications industry has been recognised and proven to have unparalleled importance. This study emphasises that $100 \%$ of entrepreneurs should be entrepreneurially oriented to improve the status of entrepreneurship and to strengthen the resilience of the enterprises and the economy in a globally cut-throat and challenging ecosystem. Lumpkin and Dess ${ }^{17,18}$ and Lumpkin et al. $^{19}$ supported the view of this study that one of the fundamental characteristics of firms that want to be successful in the long term is EO. Lumpkin and Dess ${ }^{15,16}$ defined EO as the eagerness of firms to portray proactive and transformative actions, and take calculated risk to create and exploit the environment. This definition is adopted in the current study. The EO may be used by management in the telecommunications industry as a way to unearth and capitalise on opportunities and thus invariably positively impact the firm's performance.

Telecommunications firms in Zimbabwe, despite a finite access to capital, can perform well if they exhibit and practise higher magnitudes of EO. It is on this basis that EO is appraised as a critical capability of the organisation. Several scholars ${ }^{4,5,6,7}$ designate a significant relationship between EO and financial performance. The telecommunications sector in Zimbabwe has seen rapid growth in the past decade, as many firms are emerging, but unfortunately many have also ceased to exist in short spans of time. The barriers to entry as espoused by this study are relatively low, as such the conditions for exit are also minimal. The cost structures in the sector are relatively high, as key career skills are required to sustain operations in some niche markets. However, many shops based on low-cost models exist and grey market sourcing is making its appearance in Harare. As a Third World, growing economy, there is high growth potential in this sector in Zimbabwe, yet a closer analysis comparing the country's growth rate to the region, the Southern African Development Community (SADC), would appear to indicate otherwise, and this clearly prompts the need for an understanding of the telecommunications sector.

This study sought to ascertain the influence of EO on business performance for SMMEs within the telecommunications industry, that is, the information and communications and technology (ICT) sector in Zimbabwe. The article is structured as follows: it commences by giving background on the study with a clear focus on the global trends in business and corporate EO in SMMEs in the telecommunications industry. The problem statement indicates certain specific management problems that SMMEs in the telecommunications industry are facing with regard to adaptability and time to market their products. From the research problem, the objectives and the research questions are then formulated and established. The justification for the research is subsequently discussed. The research purpose is to create and add value and allow businesses and academics to capture that value. For this purpose, a short literature review was conducted that 
examined the key and recent contributions related to the subject of EO, and a proposed construct framework was devised for carrying out the assessment of SMMEs in the telecommunications industry in Zimbabwe. Furthermore, the study discusses an appropriate methodology together with the data analysis techniques applied, and the methods for data analysis and results interpretation and synthesis.

\section{Problem statement}

The telecommunications sector in Zimbabwe has seen proliferation of many companies; however, only a few companies have evolved from SMMEs to fully fledged enterprises. The SMMEs play a significant economic role in many countries globally. According to the World Bank, ${ }^{20}$ SMMEs globally contributed over 70\% of GDP in 2014, and in Zimbabwe, 50\%. The background highlights of the study reflect that SMMEs are challenged with the constant threat of closure and many cannot morph into large and sustainable enterprises. Studies by Small Enterprise Development Corporation of Zimbabwe (SEDCO) ${ }^{21}$ on SMMEs reveal a high perishability rate of about $85 \%$, with few SMMEs surviving for more than 3 years. This study established that many of the SMMEs in the telecommunications industry are generally low margin businesses, lacking risk management, sustainability and strategic management principles, and surviving by necessity with an invariable lack in EO.

Mahmood and Hanafi $^{22}$ postulated that EO is related to growth, superior performance and longevity. High adoption of innovativeness, risk-taking and proactiveness is further advanced as key determinants for the success of firms. Globally, economies are being largely driven by technology, and information and communications players have become integral to this new paradigm. Mahmood and Hanafi's ${ }^{22}$ opinion echoes the findings of this study which postulate that despite the vast opportunities for sustained growth, Zimbabwe's information and communications sector is experiencing modest growth and high mortality rates of about $15 \%$ per annum. One then needs to ask whether EO is lacking in this sector, as companies that have adopted this key characteristic in other economies seem to be faring extremely well. Available findings from the literature submit that EO is a critical factor in SMME expansion, as reflected in previous studies based on the concept of EO. The question one thus is forced to ask is: whether the lack of EO among Zimbabwe's SMMEs in the information and communications sector is responsible for their lethargic and modest growth rates and high failure rates. ${ }^{23}$

This question can logically be looked at on the basis of two premises. Premise 1: research studies have provided the necessary support for the assumption that EO is a necessary condition (antecedent) for high performing businesses (literature review). Premise 2: The SMMEs in the telecommunications sector in Zimbabwe are low performing businesses (assuming performance indicators related to the studies substantiated in premise 1). Conclusion (also a hypothesis): Zimbabwean SMMEs in the telecommunications sector most probably lack EO (with the application of the same measurement instrument used in the studies referred to in premise 1). Accordingly, the research question is formulated as follows: What is the level of EO presence in SMMEs in the telecommunications sector in Zimbabwe? Because this level is low, the current study finds the support for premise 1 within the Zimbabwe context. The studies conducted on the influence of EO were mostly conducted in developed countries outside Zimbabwe. Zimbabwean SMMEs in the telecommunications industry make a large contribution in terms of revenue to the Zimbabwean economy, yet there is little empirical evidence available on the influence of EO on firm performance and the growth of SMMEs in Harare, Zimbabwe. This study aims to investigate this aspect and provide some insights into the Zimbabwean context.

\section{Scope of research}

This research involved repeated observations of the same telecommunications SMMEs over a long period of 12 years covering 2008-2020. This period represents the time that the Zimbabwe economy started experiencing catastrophic cash and foreign currency shortages which affected the EO of managers in the entrepreneurial context of the Zimbabwean economy. The Zimbabwe Central Bank, the Reserve Bank of Zimbabwe (RBZ), ${ }^{24}$ introduced a local currency denominated the Bond-Note (BN) and the Real Time Gross Settlement (RTGS) dollar whose values were suggested to be equal to the US dollar. The RBZ pointed to this as the period when corporate collapses in the telecommunications industry began and heightened. The introduction of the surrogate currency saw Zimbabwe's international credit ratings falling, with sovereign risk rising to the red zone beyond the $75 \%$ mark. This research was limited to SMMEs in the telecommunications sector in the City of Harare only.

\section{Entrepreneurial orientation}

Entrepreneurial orientation measures the firm's structural and systematic organised performance. It is conceptualised as the integral decision-making and business processes operations applied by an entrepreneur to act entrepreneurially., ${ }^{9,25}$ It generally speaks to a firm's strategic orientation and the procedures the firm uses to innovate, take risks and act autonomously and proactively to compete aggressively. The definition of EO in this article is pinned on the work of Miller, ${ }^{27}$ expanded by Covin ${ }^{28}$ and Slevin ${ }^{29}$ and then supplemented by Lumpkin and Dess ${ }^{17,30,31}$ and Dess, Lumpkin, and Covin..$^{31}$ The EO in businesses is recognised by the presence of five attributes, namely risk-taking, proactiveness, innovativeness, competitive aggressiveness, and autonomy. The literature revealed that the measured presence of these attributes in businesses relates to their measured business performance. The attributes are described in the following section.

\section{Risk-taking}

Risk-taking is an EO associated with entrepreneurship during the emerging stages. Risk-taking relates to the 
uncertain endeavours undertaken by entrepreneurs working for personal attainment, but has since been broadly applied to companies where leaders commit huge outlays to projects whose outcomes are uncertain. Risk-taking is a move towards bold actions such as investing in uncertain markets and committing a large amount of capital resources to investments with uncertain outcomes. Tshikovhi, and Shambare $^{32}$ described an entrepreneur as a rational decision maker assuming risk and providing the management of the firm. They also described risk-taking as an act that commits huge capital resources to opportunities which may have a high probability of uncertainty. There is no one-size-fit-all method for measuring risk-taking in SMMEs as they are oriented differently. Organisations can conduct surveys or experiments to measure the presence of risk-taking behaviour in their enterprise. The risk-taking construct represents the capability and ability of an organisation's strategic demeanour which alludes to the firm's willingness and ability to commit resources for projects with uncertain success. In this study, experimental surveys established that in regard to risk-taking processes, there is $45 \%$ risk averse entrepreneurs; $15 \%$ risk neutral and 40\% risk lovers, and their risk philosophical standing makes these entrepreneurs perform differently in the telecommunications sector in Harare.

\section{Proactiveness}

Proactiveness is a firm characteristic that allows it to positively forecast opportunities and sphere of influence in terms of products, services and consumer demand. Proactivity differs fundamentally from affective traits like well-being and from cognitive traits like locus of control. A proactive disposition is a tendency to initiate and maintain actions that directly alter the surrounding environment. Proactiveness is indicated internally and externally, and is measured scientifically using proactive personality scales. This characteristic is said to be the core of primary economic discernment in entrepreneurship. A financier is considered to be an identifier of opportunities in the marketplace and proactively engage in them. ${ }^{19}$ Positive performing SMME firms with high sustainable profit levels are market leaders, rather than market followers. Proactiveness involves the capacity to take on projects whenever the situation demands that such action be taken. Proactiveness is associated with first-mover actions and forward-looking perspectives and actions that anticipate future demand. By conducting proactive personality scales, this study exposed that $75 \%$ of the enterprises in the telecommunications sector in Harare are not proactive because of a lack of foreign currency available to buy the necessary resources needed for their entrepreneurial activities.

\section{Innovativeness}

Innovativeness is concerned with the nature and form of goods and services a firm introduces into the marketplace. Schumpeter ${ }^{33,34}$ argued that innovativeness is linked to entrepreneurship in creating new combinations of resources and remodelling old products and services deemed acceptable by consumers. The EO contextually portrays innovativeness narrowly, emphasising the significance of technological advancements to the firm, including shifts in its product lines. Innovativeness replicates a firm's propensity to engage in new ideas, novelty, experimentation and imaginative processes, ${ }^{19}$ The resultant innovated products, services, or technological developments take the organisation to a brand-new paradigm of success. ${ }^{35}$ According to Covin et al., ${ }^{36}$ innovativeness represents a basic eagerness to depart from current technologies or practices, and venture outside the current state of the art. The current study pooled the studied firms' innovativeness, taking in diversified styles, nature and forms. The evidence from the research conducted exposed that in the broadest view, $80 \%$ of innovativeness may transpire on a continuum from a modest inclination to either try a new product line to a passionate commitment to master the latest brands of products or technological advancements in the telecommunications sector in Harare. Innovation is vital to telecommunications sector entrepreneurship as it directly contributes to a country's economic growth and research.

\section{Competitive aggressiveness}

In this article, competitive aggressiveness is concerned with the way telecommunications companies engage with their competitors, focusing on companies which are against direct competition and companies that aggressively pursue competitors' markets. Vij and $\mathrm{Bedi}^{37}$ asserted that competitive aggressiveness is the firm's desire to face its competitors vigorously to achieve entry position and outpace the incumbent industry rivalry in the marketplace. Kraus et al. ${ }^{38}$ postulated that competitive aggressiveness mirrors the unconventional goal of a firm comparable to relying on outmoded systems of competing. Competitive aggressiveness is utilised in this study as a measure of how firms in the telecommunications sector in Harare deal with strengths, weaknesses, opportunities and threats. It also refers to the firm's responsiveness aimed at achieving a competitive edge. ${ }^{30}$ In available sources of related literature, the terms proactiveness and competitive aggressiveness are used interchangeably; however, there is a thin line between the two concepts. Proactiveness is focused on the relationship of the firm to the market opportunities in creating demand, while competitive aggressiveness is concerned with the firm's relationship with the competitors in line with its marketing philosophy.

\section{Autonomy}

Autonomy is the self-reliant and independent achievement of an entrepreneur or a team in bringing forth a strategic plan, vision and mission, and carrying it through to completion without being pulled back by overly stringent organisational limitations. ${ }^{18}$ According to Lumpkin et al., ${ }^{30}$ this autonomy seems to primarily have face validity in large organisations and researchers contextualise it to small companies, obtaining statistically significant findings. From the findings of this study, key informants agreed unanimously that the action of autonomy focuses on self-reliance and 
independent action of an individual or a team in achieving the strategic goals of the enterprise. In an entrepreneurial context, autonomy refers to actions taken that are free from governmental constraints. The autonomous behaviour of entrepreneurs is guided by several factors which include legal, economic, social, political and technological legitimacy and expertise. Autonomy as an EO was attested to amongst the respondents as being a quintessential determinant factor in the telecommunications industry in Zimbabwe, which is heavily controlled by the cumbersome operational obligations imposed by the Postal and Telecommunications Regulatory Authority of Zimbabwe (POTRAZ). These obligations limit the entrepreneurs' performance.

\section{Business performance}

The available information on performance reveals consensus among the researchers on the appropriate measures for business performance indicators. There is broad diversity in the objective and subjective measures of performance; these are financial and non-financial measures leading to diversities in the $\mathrm{EO}$ and performance relationships. The question that arises is what the appropriate form of performance measurement is. Business performance has been accepted in research as an objective measure of performance compared to subjective measures. Objective data is not easily gathered according to the works of Short et al. ${ }^{39}$; accordingly, respondents were reluctant to volunteer certain gate-keeping information. Owners and top managers are disposed to volunteer objective performance evaluation, which divests reliability for the study. ${ }^{40,41}$ Performance is seen as multidimensional in character, and it is preferable to merge multiple measurements of performance accurately. ${ }^{31,40}$

\section{Small, micro and medium enterprises}

The terms SMMEs and small businesses are used interchangeably. There is no standard agreed definition for small businesses as this depends on many determinants such the size of the economy, the nature and number of resources available, and the objectives and goals of the supporting agent. Kuratko ${ }^{42}$ defined a small business as one which is independently operated and not significantly dominant in its field of operation. The European Union (EU) Member States traditionally have different definition constituents of an SMME; for example, Germany has a limit of 250 employees while Belgium has stated the limit of 150 employees. The EU's definition of an SMME is companies with less than 10 employees as 'micro', those with less than 50 employees as 'small', and those with less than 250 as 'medium. In the United States of America (USA), small business is defined by the number of employees and more often than not it refers to companies with fewer than 100 employees, while medium-sized business are considered to have less than 500 employees. Small Enterprise Development Corporation of Zimbabwe ${ }^{21}$ defined a small and medium enterprise in Zimbabwe as a firm with up to 100 workers and maximum annual sales turnover of
US\$1 500 000. This study further distinguished non-formal enterprises and SMMEs based on legislation. Non-formal entrepreneurs are categorised as those firms that are unregistered according to the Company Act (Chapter 190) and the Factory and Works Act (Chapter 283), while formal SMMEs are those that are registered as per the Companies Act (Chapter 190). The researcher's focus was on those companies whose businesses are formalised and fall within the telecommunications industry in Zimbabwe.

\section{Entrepreneurial orientation and performance}

The results of this study reflected a positive correlation as proved by +1 between $\mathrm{EO}$ and the firm's sustainable performance. A firm performance is a multi-faceted concept to the extent that the relationship between EO and the performance of a firm depends on the non-definitive indicators used to assess performance. A customary comparison of EO and performance rests on financial and non-financial measures. Financial measures are not limited to factors like sales growth and return on investments. ${ }^{43}$ Self-reported data therefore offers greater opportunities for testing multiple dimensions of performance, such as comparisons with competitors. ${ }^{40}$ Nonfinancial measures include achievements like satisfaction and global success ratings. Rauch ${ }^{44}$ suggested that it is reasonable to assume that there is greater relationship between EO and financial performance than between $\mathrm{EO}$ and non-financial performance. Firms that score high on innovativeness and proactiveness, and also have a high propensity for risk-taking, are bound to have an increase in the sales of their products and services than firms that do not. ${ }^{45,46,47,48}$ Wiklund and Shepherd ${ }^{40}$ summarised the descriptions of works done by many researchers. ${ }^{27,37,49,50}$ The $\mathrm{EO}$ is about readiness to reengineer and regenerate market contributions, taking risks on new products, services and markets. In addition, EO calls for more proactivity than competition in view of upcoming market openings. This research analysed this phenomenon in the Zimbabwean context.

The analysis of the findings boosted concerns that entrepreneurs in the telecommunications industry are in dire need of orientation to enable them to provide an acceptable standard of service delivery effectively and efficiently to consumers.

Figure 1 shows the variables that constitute the EOs that stand to impact and influence the performance of SMMEs

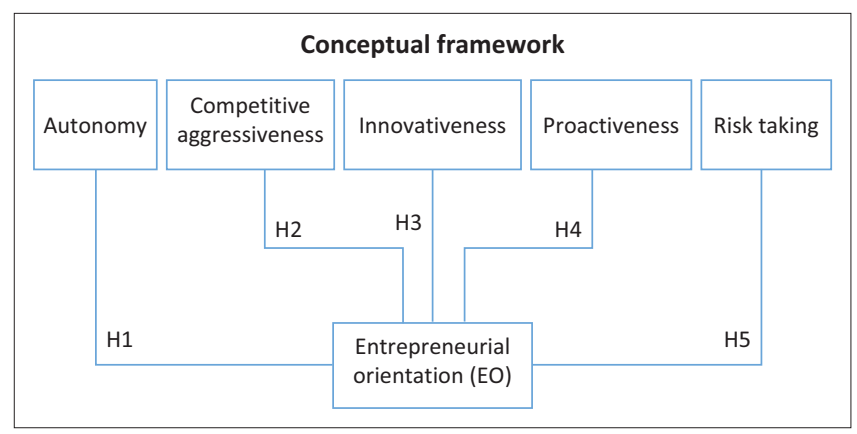

FIGURE 1: Conceptual framework (courtesy of the study). 
in the telecommunications industry in Zimbabwe. This study found that entrepreneurs in this sector are greatly concerned with autonomy, proactiveness, innovativeness, competitive aggressiveness and risk-taking.

\section{Methodology}

Research methodologies are systems of explicit rules for research based on which claims of knowledge are evaluated. The overall research question for this article concerns the impact of EO on business performance for SMMEs in the telecommunications industry of Zimbabwe. This part of the study focuses on the methods, techniques and tools used in the classification, gathering and management of data, as well as data analysis. ${ }^{51}$ It covers the areas concerned with design, methods to be used, target population, research instrument to be applied, data collection procedures, justification of the approaches used and data analysis. The research adopted a positivist approach because the researcher is independent from the subject of the research. Consequently, the research adopted the telecommunications sector in Zimbabwe as the unit of analysis. The research followed an explanatory cum quantitative approach. During the exploration of the effect of EO on firm performance, initial empirical field data from interviews were considered apposite since that empirical evidence could furnish the essential elasticity of the study. ${ }^{52}$

Positivism in this study was also emphasised by the fact that the observations were quantifiable and follow a highly structured methodology to enable replication of results. The research uses a deductive approach as a theory was developed and a hypothesis formulated from which the research was designed to test each hypothesis. The findings reflected causal relationships between variables which the research sought to explain, for instance how strategic risk-taking impacts business performance in Zimbabwean information and communications SMMEs. The research was exploratory and descriptive in nature.

Surveys were found to be useful for the research in question, and a survey approach was used because of the ability it offers in terms of data collection. The method is used to describe populations that are too large to observe directly and has much flexibility and versatility.

The study was cross-sectional and covered an analysis of homogenous events that occurred at the selected SMMEs for the period between 2015 and 2020. In the research in question, owners and middle and senior management of the selected telecommunications SMMEs in Harare were selected as the study population.

\section{Population}

According to the World Bank, ${ }^{16}$ there is a population of 45041 registered establishments (formalised businesses) in Zimbabwe of which about $80 \%$ are classified as SMMEs according to the SEDCO classification. Records of the Computer Society of Zimbabwe (CSZ) and the Computer
Suppliers Association of Zimbabwe (CSAZ) reveal a membership of approximately 3700, of which $70 \%$ is classified as SMMEs using the SEDCO ${ }^{21}$ classification criteria. Out of that $70 \%, 50 \%$ of the businesses are in Harare and Bulawayo as the two largest cities in the country.

\section{Sampling procedure and study sample}

Purposive sampling and judgemental sampling were used, with the researcher's judgement being used to select population members who were good prospects for accurate information. The 2016 Harare Informal Sector Business Survey (ISBS) uses a new mode for measuring these informal business segments. In describing the potential clustering of informal businesses, the analysis used area-based sampling, termed (stratified) 'adaptive cluster sampling' (ACS). The ACS selects a sample of starting grids (usually squares), which constitute the starting point for the fieldwork. In the current study, all informal businesses in the quadrant were enumerated, using a 2-3 min questionnaire (short-form questionnaire). A subset of businesses selected randomly was targeted with a $20 \mathrm{~min}$ long-form questionnaire. The total grid area captured all of central municipal Harare, with quadrants of size 200 by $200 \mathrm{~m}$. The sampling was based on four quadrants derived from operational units which included: the SMMEs operating from the Central Business District (CBD), industrial zones including Workington and Southerton, Masasa and Graniteside, and SMMEs operating in upmarket areas where the elites of Zimbabwe reside (in this case Borrowdale Brooke was randomly chosen), as well as SMMEs operating from home offices (Table 1).

Table 1 reflects that a large number of entrepreneurs in the telecommunications industry in Zimbabwe are concentrated in the CBD with 300 enterprises, with the fewest operators being in Workington and Southerton with 100 enterprises. This may be because these areas are designated for heavy industries.

\section{Data collection techniques and instruments}

The researcher used primary data for the research. Semistructured interviews and structured questionnaires were used as the primary data collection methods. In the development of the instruments, a five-point Likert scale was used structured as follows: strongly agree, agree, non-aligned, disagree and strongly disagree. These structures offered reasonable validity and reliability of the data gathered. The initial draft interview script was

TABLE 1: Sample population framework

\begin{tabular}{lccc}
\hline Operational unit & $\begin{array}{c}\text { Total } \\
\text { population }\end{array}$ & $\begin{array}{c}\text { Sample } \\
\text { size }\end{array}$ & $\begin{array}{c}\% \text { of } \\
\text { population }\end{array}$ \\
\hline SMMEs operating from the CBD & 300 & 110 & 28 \\
SMMEs in Workington, Southerton & 100 & 43 & 43 \\
SMMEs in Masasa, Graniteside & 200 & 50 & 25 \\
SMMEs in uptown Borrowdale Area & 200 & 60 & 30 \\
SMMEs from home offices & 200 & 45 & 23 \\
\hline Total & $\mathbf{1 0 0 0}$ & $\mathbf{3 0 8}$ & $\mathbf{3 1}$ \\
\hline
\end{tabular}

CBD, Central Business District; SMME, small, micro and medium enterprises. 
piloted with five SMMEs which were randomly chosen. The manuscript and the questionnaires were revised before used for gathering data for the key research. In addition, face-to-face interview sessions were held with the owners, and middle and senior management of the telecommunications SMMEs. The interviews were not expected to last more than $2 \mathrm{~h}$. Many of the face-to-face interviews were done in the offices of the interviewees. The interview guides incorporated the firm's environment, the level of responsiveness of EO, strategic risk-taking, autonomy, competitive aggressiveness, innovativeness, proactiveness and business performance. Interviews were recorded with the permission of the participants and transcribed immediately after the interview sessions. Transcripts were sent to the participants for refinement as necessary. ${ }^{53}$

\section{Data management and analysis}

Quantitative regression and correlation analysis were applied in data analysis in this study. Considering the number of variables to be assessed, multiple regressions were employed using appropriate tools such as Statistical Packages and Software Services (SPSS). To observe relationships among the variables that were impacted by $\mathrm{EO}$, correlation analysis was conducted. Bias was prevented by giving participants the opportunity to highlight the factors they consider to be important in their situations with regard to the impact of $\mathrm{EO}$, instead of structuring the research questions around the EO attributes. ${ }^{53}$ Data management and analysis procedures and processes postulated by Miles and Huberman ${ }^{54}$ were performed. The data analysis was constituted by three simultaneous activities: data reduction, display and didacticism and/or confirmation. The gathered statistics were abridged and extricated for the purpose of condensation, 55,56 while data display focused on organising and assembling information, which consequently allowed the researcher to reach conclusions. ${ }^{54}$ The analysed data was compared to the findings of the literature review section to come up with a comprehensive report on $\mathrm{EO}$.

Figure 2 reflects that the SMMEs were concentrated in the CBD and peripheral areas such as Southerton and Workington. These areas are allocated for heavy industry and there is space for high powered machinery; consequently the place is noisy because of heavy machinery. In the CBD, it is quieter which telecommunications businesses require. The other noteworthy factor is the high number of offices in the CBD.

\section{Impact of entrepreneurial orientation on the performance of small, micro and medium enterprises in the telecommunications industry}

The study revealed relationships between performance and EOs. Figure 3 shows that there is a $27 \%$ performance impact (PI) when there is autonomy. In this case, the implication is that entrepreneurs for SMMEs in the telecommunications industry enjoy autonomy which seems to be the key to successful performance for entrepreneurs. The orientations also revealed that risk-taking is the least preferred orientation in SMMEs in the telecommunications industry in Zimbabwe. However without risk-taking, entrepreneurial performance is not sustained.

Competitive aggressiveness and innovativeness carry the same weight in the relationship between performance and EO at $19 \%$, as attested by the study respondents. The study found strong relationships between EO and enterprise PI and vice versa. The correlation analysis reflected positive significant relationships between EOs and PI in Zimbabwean SMMEs in the telecommunications industries. The association is linear, PI increases or decreases a fixed amount in line with a unit increase or decrease in EO. The other technique that this research used here is stepwise regression, which involved estimating the best straight line to summarise the associations. Complete correlation between PI and EO was found as expressed by +1 . Accordingly, EO improves as PI increases indicating

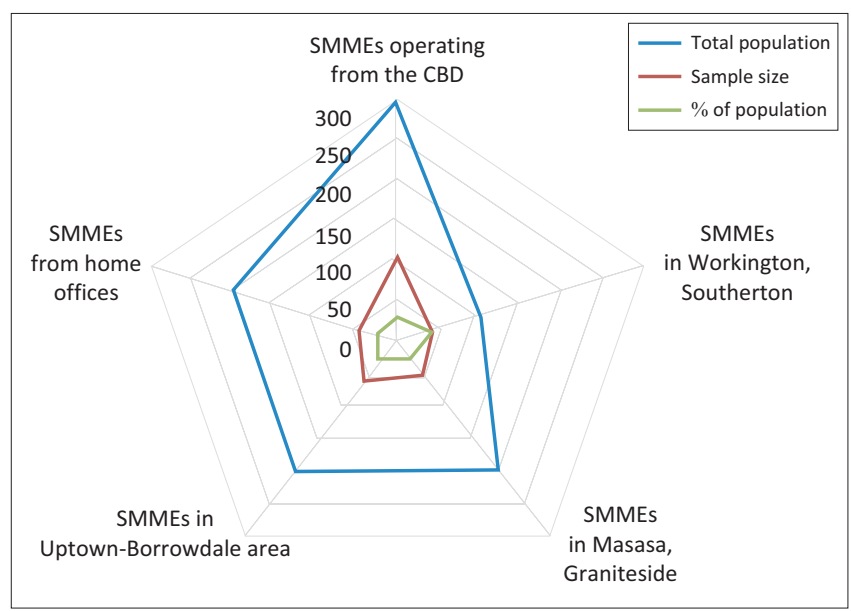

SMMEs, small, micro and medium enterprises; CBD, Central Business District. FIGURE 2: Distribution of Telecommunications SMMEs in and around Harare.

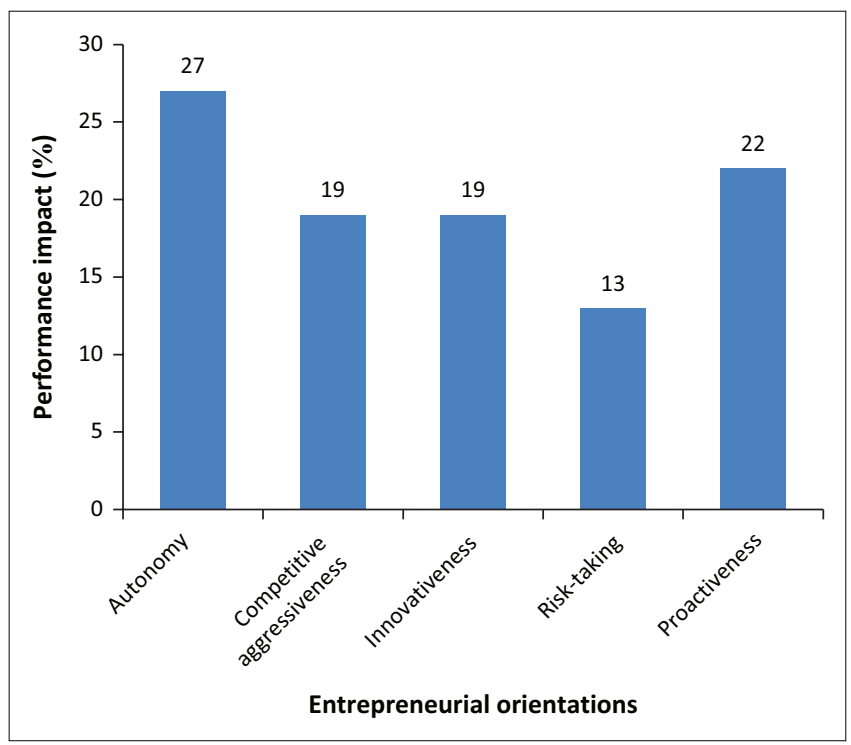

FIGURE 3: Performance impact of entrepreneurial orientations. 
that the correlation is positive; when EO declines, the PI decreases. ${ }^{57}$

\section{Limitations}

The study carried out faced a few limitations. Firstly, the research is limited to the SMMEs in the information and communications sector in Zimbabwe, and as such it may be difficult to make inferences to other sectors. The research also ignored other moderating constructs like environment and access to capital which may have a bearing on the results. Also, the research was limited to the city of Harare only, and as such, there may be differences in terms of EO for this city and other cities and towns in Zimbabwe and outside Zimbabwe. There is also a limitation in terms of measuring performance which can either be objective or subjective. However, this study tried to be objective by approaching the issues from a rational perspective.

\section{Gap and contribution}

The research sought to add to the existing body of knowledge useful to academics as well as assisting telecommunications business owners and practitioners with strategy formulation, implementation, development, and practice. It will help shape the practices underpinning sustained competitive advantage for the firms in the sector and could be used in other sectors as well. It will also assist in explaining the function of EO with regard to business performance. ${ }^{24}$ The research gap entails the limited scholarly research conducted and published in Zimbabwe to date and the bearing of $\mathrm{EO}$ on the business execution of SMMEs in the telecommunications sector. This investigation is specific to SMMEs in the telecommunications sector and in Zimbabwe. The context of the research is peculiar to Zimbabwe and the results can be adopted and used in the Zimbabwean context and might be adopted by other nations that may potentially find themselves in precarious economic conditions such as those currently prevailing in Zimbabwe.

\section{Conclusion}

The tenets of EO have been successfully adopted by progressive economies resulting is phenomenal economic and social status growth as evidenced in such places as China and Japan. In conclusion, there are valid and compelling reasons for conducting this study as the literature is readily available and the need for the study is apparent and the Zimbabwean SMME sector will certainly benefit from it. In a nutshell, one can justifiably assert that EO is quintessential to triggering the PI, which is the best practice of an ongoing, two-way operation. Business performance helps the entrepreneur to develop goals and objectives that benefit the team, the organisation, and the individual, rather than a once-off operational goals that affect the industry. The EO was investigated to promote the commercial effectiveness of an enterprise, a department or an individual to achieve strategic objectives and improve the expected results of
SMMEs in the telecommunications sector in Zimbabwe. This study also found that entrepreneurs in SMMEs need autonomy, proactiveness, innovativeness, competitive aggressiveness and risk-taking in declining proportions. These are also correlated to PI in +1 positive Pearson correlation coefficient levels which reflect that they are highly interdependent. Improvement in one of them means increased productivity for the entity. Policymakers and state entrepreneurial agencies like Small Enterprise Development Corporation should evaluate the EO and formulate favourable policies to stimulate the growth and development of SMMEs for they are the economic drivers of employment creation and revenue creation.

\section{Acknowledgements}

The author acknowledges the Almighty God for granting him the wisdom to put up this research as well as to acknowledge Prof. Benyera in proofreading the article. It is also quintessential for the author to offer gratitude to Walter Sisulu University Mthatha Campus, for supporting the research activities to immeasurable limits.

\section{Competing interests}

The author declares that he has no financial or personal relationships that may have inappropriately influenced him in writing this article.

\section{Author's contributions}

The author conducted the research for this article from the conceptualisation and contextualisation of the idea up to the final write up of the article.

\section{Ethical considerations}

This article followed all ethical standards for research without direct contact with human or animal subjects.

\section{Funding information}

The author received specific funding from University of South Africa for publication fees.

\section{Data availability}

Data will be made available from the author upon reasonable request, there are no figures from the raw data, the data used was primary data, which had no restrictions.

\section{Disclaimer}

The views and opinions expressed in this article are those of the author and do not necessarily reflect the official policy or position of any affiliated agency of the author.

\section{References}

1. Rosen W. The most powerful idea in the world: A story of steam, industry, and invention. New York, NY: Random House; 2010. 
2. Brown EK. The fourth industrial revolution: Will Africa be ready? [homepage on the Internet]. Ghana: ACET: The African Center of Economic Transformation; 2020 [cited 2020 Dec 28]. Available from: www.acetforafrica.org

3. Ling YAN, Simsek Z, Lubatkin MH, Veiga JF. Transformational leadership's role in promoting corporate entrepreneurship: Examining the CEO-TMT interface. Acad Manag J. 2008;51(3):557-576. https://doi.org/10.5465/amj.2008.32626023

4. Anderson BS, Kreiser PM, Kuratko DF. Reconceptualizing entrepreneurial orientation. Strateg Manag J. 2015;36(10):1579-1596. https://doi.org/10.1002/ smj.2298

5. Basso O, Fayolle A, Bouchard V. Entrepreneurial orientation: The making of a concept. Int J Entrepreneurship Innov. 2009;10(4):313-321. https://doi.org/ 10.5367/000000009790012327

6. Covin JG, Wales WJ. The measurement of entrepreneurial orientation Entrepreneurship Theory Pract. 2012;36(4):677-702. https://doi.org/10.1111/ j.1540-6520.2010.00432.x

7. Edmond VP, Wiklund J. The historic roots of entrepreneurial orientation research Historical Foundations of Entrepreneurship Research. Cheltenham: Edward Elgar Publishing Ltd., 2010; p. 142-160.

8. Miller DA. Reflection on EO research and some suggestions for the future Entrepreneurship Theory Pracy. 2011;35(5):873-894. https://doi.org/10.1111/ j.1540-6520.2011.00457.x

9. Covin JG, Lumpkin GT. Entrepreneurial orientation theory and research: Reflections on a needed construct. Entrepreneurship Theory Pract. 2011;35(5):855-872. https://doi.org/10.1111/j.1540-6520.2011.00482.x

10. Anderson R, Shemilt I. The role of economic perspectives and evidence in systematic review. In: Shemilt I, Mugford M, Vale L, editors. Evidence-based decisions and economics: Health care, social welfare, education and criminal justice. 2nd ed. Oxford: Wiley-Blackwell, 2010; p. 23-42.

11. Global Entrepreneurship Monitor. 2014 Global Report. London: London Business School; 2014.

12. Lukes M, Laguna M, editors. Entrepreneurship: A psychological approach. Prague: Oeconomica; 2012.

13. Covin JG, Miller D. International entrepreneurial orientation: Conceptua considerations, research themes, measurement issues, and future research directions. Entrepreneurship Theory Pract. 2014;38(1):11-44. https://doi.org/ 10.1111/etap.12027

14. Wales WJ, Gupta VK, Mousa FT. Empirical research on entrepreneurial orientation: An assessment and suggestions for future research. Int Small Bus 2013;31(4):357-383. https://doi.org/10.1177/0266242611418261

15. Zimbabwe Agenda for Sustainable Socio-Economic Transformation (Zim Asset) Towards an empowered society and a growing economy. Harare: Government of Zimbabwe Printers; 2013.

16. World Bank. World Bank data [homepage on the Internet]. 2016 [cited $2021 \mathrm{Ma}$ 10]. Available from: http://data.worldbank.org/

17. Lumpkin GT, Dess GG. Clarifying the entrepreneurial orientation construct and linking it to performance. Acad Manage Rev. 1996;21(1):135-172. https://doi. org/10.5465/amr.1996.9602161568

18. Lumpkin GT, Dess GG. Linking two dimensions of entrepreneurial orientation to firm performance: The moderating role of environment and industry life cycle. Bus Ventur. 2001;16(5);429-451. https://doi.org/10.1016/S0883-9026(00)00048-

19. Lumpkin GT, Brigham, KH, Todd W. Moss. Long-term orientation: Implications for the entrepreneurial orientation and performance of family businesses. Entrepreneurship Reg Dev. 2010;22(3-4):241-264. https://doi.org/10.1080/08985 621003726218

20. World Bank. The International Bank for reconstruction and development. Washington, DC: World Bank; 2015.

21. SEDCO. Regional assessment reports. Harare: Government Printers. 2014

22. Mahmood R, Hanafi N. Entrepreneurial orientation and business performance of women-owned small and medium enterprises in Malaysia: Competitive advantage as a mediator. Intl J Bus Soc Sci. 2013;4(1):82-90.

23. Kreiser PM, Davis JL. Entrepreneurial orientation and firm performance: The unique impact of innovativeness, proactiveness, and risk-taking. J Small Bus \& Entrship. 2010; 23(1):39-51.

24. Zaato SG, Mohammad I, Uthamaputhran S, Owusu-Ansah W, Owusu J. Chapte 96: The influence of entrepreneurial orientation on SME performance in Ghana: The role of social capital and government support policies. Berlin: Springe Science and Business Media LLC; 2021

25. Dess GG, Lumpkin GT, Covin JG. Entrepreneurial strategy making and firm performance: Tests of contingency and configuration models. Strateg Manag 1997;18(9):677-695. https://doi.org/10.1002/(SICI)1097-0266(199710)18:9\%3C 677::AID-SMJ905\%3E3.0.CO;2-Q

26. Mahi U, Mustafa MC, Maruf MD, Ullah MD. Barriers and incentives for youth entrepreneurship start-ups: Evidence from Bangladesh. Global J Manag Bus Res [serial online]. 2015 [cited 2021 Mar 19]. Available from: https://journalofbusiness. org/index.php/GJMBR/article/view/1621

27. Rauch A. Let's put the person back into entrepreneurship research: A metaanalysis on the relationship between business owners' personality traits, business creation, and success. Eur J Work Organ Psychol. 2007;16(4):353-385. https://doi. org/10.1080/13594320701595438

28. Miller D. The correlates of entrepreneurship in three types of firms. Manag Sci. 1983;29(7):770-792. https://doi.org/10.1287/mnsc.29.7.770
29. Covin J., Slevin DP. The influence of organization structure on the utility of an entrepreneurial top management style. J Manag Stud. 1988;25(3):217-234. https://doi.org/10.1111/j.1467-6486.1988.tb00033.x

30. Lumpkin GT, Dess GG. Strategy in family business: Recent findings and future challenges. The Landscape of Family Business. New York, NY: Edward Elgar; 2013.

31. Lumpkin GT, Dess GG. Academy of management. Acad Manag Rev. 2006;21(1):135-172. https://doi.org/10.5465/amr.1996.9602161568

32. Tshikovhi N, Shambare R. Entrepreneurial knowledge, personal attitudes, and entrepreneurship intentions among South African Enactus students. Prob Perspect Manag. 2015;13(1):152-158.

33. Schumpeter JA. Theorie der wirtschaftlichen Entwicklung (Theory of economic development). 4th ed. Berlin: Duncker \& Humblot; 1934.

34. Schumpeter JA. Capitalism, socialism, and democracy [homepage on the Internet]. University of Illinois at Urbana-Champaign's Academy for Entrepreneurial Leadership Historical Research Reference in Entrepreneurship 1942 [cited 2020 July 26]. Available from: https://ssrn.com/abstract=1496200

35. Swierczek FW, Ha TT. Entrepreneurial orientation, uncertainty avoidance and firm performance. Int J Entrepreneurship Innov. 2003;4(1):46-58. https://doi. org/10.5367/000000003101299393

36. Covin JG, Green KM, Slevin DP. Strategic process effects on the entrepreneuria orientation - Sales growth rate relationships. Entrepreneurship Theory Pract. 2006;30(1):57-81. https://doi.org/10.1111/j.1540-6520.2006.00110.x

37. Vij S, Bedi HS. Relationship between entrepreneurial orientation and business performance: A review of literature. IUP J Bus Strateg. 2012;IX(3):17-31.

38. Kraus SI, Frese M, Friedrich C, Unger, JM. Entrepreneurial orientation: A psychological model success among southern Africa small business owners. Eur Work Organ Psychol. 2005;14(3):315-344. https://doi.org/10.1080/13594 320500170227

39. Short JC, Payne GT, Brigham KH, Lumpkin GT, Broberg, JC. Family firms and entrepreneurial orientation in publicly traded firms: A comparative analysis of the S\&P 500. Fam Bus Rev. 2009;22(1):9-24. https://doi.org/10.1177/ 0894486508327823

40. Wiklund J, Shepherd D. Entrepreneurial orientation and small business performance: A configurational approach. J Bus Ventur. 2005;20:71-91. https:// doi.org/10.1016/j.jbusvent.2004.01.001

41. Wiklund J. The sustainability of the entrepreneurial orientation-performance relationship. Entrepreneurship Theory Pract. 1999;24(1):37-49. https://doi. org/10.1177/104225879902400103

42. Kuratko DF. Entrepreneurship: Theory, process, practice. 11th ed. Mason, $\mathrm{OH}$ Cengage/Southwestern Publishers; 2020.

43. Covin JG, Slevin DP, Schultz RL. Implementing strategic missions: Effective strategic, structural, and tactical choices. J Manag Stud. 2001;31(4):481-506. https://doi.org/10.1111/j.1467-6486.1994.tb00627.x

44. Rauch A, Wiklund J, Lumpkin G, Frese M. Entrepreneurial orientation and business performance: An assessment of past research and suggestions for the future. Entrepreneurship Theory Pract. 2009;33(3):761-787. https://doi.org/10.1111/ j.1540-6520.2009.00308.x

45. Bchini B. Entrepreneurial orientation and firms' performance: The case of Tunisian companies. Int J Econ Com Manag. 2015;III(3):1-15.

46. Jain R, Ali SW. Self-efficacy beliefs, marketing orientation and attitude orientation of Indian entrepreneurs. J Entrepreneurship. 2013;22(1):71-95. https://doi. org/10.1177/0971355712469155

47. Owoseni OO, Adeyeye TC. The role of entrepreneurial orientations on the perceived performance of small and medium-scale enterprises (SMMEs) in Nigeria. Oyo: Ajayi Crowther University; 2011.

48. Azlin SA, Amran R, Afiza AA, Zahariah MZ. The impact of entrepreneurial orientation on business performance: A study of technology-based SMMEs in Malaysia. Procedia Soc Behav Sci. 2013;130:46-53. https://doi.org/10.1016/j. sbspro.2014.04.006

49. Knight GA. Emerging paradigm for international marketing: The born global firm East Lansing, MI: Michigan State University; 1997.

50. Zahra SA, Covin JG. Contextual influences on the corporate entrepreneurship performance relationship: A longitudinal analysis. J Bus Ventur. 1995;10(1):43-59. https://doi.org/10.1016/0883-9026(94)00004-E

51. Golafshani N. Understanding reliability and validity in qualitative research: The qualitative report. 2003;8(4):597-606.

52. Nwekpa KC. Entrepreneurial orientation and business performance amongst microbusinesses in Nigeria. IOSR J Bus Manag (IOSR-JBM). 2017;19(7):45-53.

53. Leedy PD, Ormrod JE. Practical research: Planning and design. 8th ed. Englewood Cliffs, NJ: Pearson Merrill Prentice Hall; 2005.

54. Naman JL, Slevin DP. Entrepreneurship and the concept of fit: A model and empirical tests. Strateg Manag J. 1993;14(2):137-153. https://doi.org/10.1002/ smj.4250140205

55. Miles MB, Huberman AM. Qualitative data analysis: An expanded sourcebook Thousand Oaks, CA: Sage; 1994

56. Robson C. Real world research: A resource for social scientist and practitionerresearchers. 2nd ed. Oxford: Wiley-Blackwell; 2002.

57. Saunders $M$, Lewis $P$, Thornhill A. Research methods for business students. Essex: Financial Times/Prentice Hall; 2007. 